\title{
A High Spatial Resolution FBG Sensor Array for Measuring Ocean Temperature and Depth
}

\author{
Li WANG ${ }^{1,2}$, Yongjie WANG ${ }^{1,2 *}$, Jianfeng $\mathrm{WANG}^{3}$, and Fang $\mathrm{LI}^{1,2}$ \\ ${ }^{1}$ State Key Laboratories of Transducer Technology, Institute of Semiconductors, Chinese Academy of Sciences, Beijing \\ 100083, China \\ ${ }^{2}$ College of Materials Science and Opto-Electronic Technology, University of Chinese Academy of Sciences, Beijing \\ 100049, China \\ ${ }^{3}$ Institute of Oceanology, Chinese Academy of Sciences, Qingdao 266071, China \\ *Corresponding author: Yongjie WANG Email:wyj@semi.ac.cn
}

\begin{abstract}
Exploring and understanding the ocean is an important field of scientific study. Acquiring accurate and high-resolution temperature and depth profiles of the oceans over relatively short periods of time is an important basis for understanding ocean currents and other associated physical parameters. Traditional measuring instruments based on piezoelectric ceramics have a low spatial resolution and are not inherently waterproof. Meanwhile, sensing systems based on fiber Bragg grating (FBG) have the advantage of facilitating continuous measurements and allow multi-sensor distributed measurements. Therefore, in this paper, an all-fiber seawater temperature and depth-sensing array is used to obtain seawater temperature and depth profiles. In addition, by studying the encapsulation structure of the FBG sensors, this paper also solves the problem of the measurement error present in traditional FBG sensors when measuring seawater temperature. Through a theoretical analysis and seaborne test in the Yellow Sea of China, the sampling frequency of the all-fiber seawater temperature and depth profile measurement system is $1 \mathrm{~Hz}$, the accuracy of the FBG sensors reaches $0.01{ }^{\circ} \mathrm{C}$, and the accuracy of the FBG depth sensors reaches $0.1 \%$ of the full scale. The resulting parameters for these sensors are therefore considered to be acceptable for most survey requirements in physical oceanography.
\end{abstract}

Keywords: Fiber Bragg grating; temperature-depth profile; cross-sensitivity; seaborne test verification

Citation: Li WANG, Yongjie WANG, Jianfeng WANG, and Fang LI, "A High Spatial Resolution FBG Sensor Array for Measuring Ocean Temperature and Depth," Photonic Sensors, 2020, 10(1): 57-66.

\section{Introduction}

Measuring and studying the temperature variations at different depths of the oceans is one of the most important components of oceanographic research [1]. It is of great significance for hydrological observations [2], meteorology [3, 4], navigation [5], fishing [6], hydroacoustics [7], and maritime operations [8] to obtain high-spatial and temporal resolution and accurate measurements of ocean temperature and depth profiles.

In recent years, a seawater temperature-depth measurement technology has become an interest of scientists studying physical oceanography [9-11]. In 1989, Tsuchiya et al. used a conductivitytemperature-depth (CTD) profiler and discrete

Received: 1 December 2018 / Revised: 6 February 2019

(C) The Author(s) 2019. This article is published with open access at Springerlink.com

DOI: $10.1007 / \mathrm{s} 13320-019-0550-0$

Article type: Regular 
water-sample measurements to identify the depths of various deep-reaching fronts in relation to the large-scale circulation and distribution of mode waters. However, the use of fixed-point CTD profilers makes it necessary to stop the ship, while the sampling is itself at a point, leading to a very low level of efficiency in terms of acquiring data [12, 13]. From 2005 to 2006, Sloyan et al. measured the temperature and salinity of seawater in the Southeast Pacific using an expendable conductivitytemperature-depth (XCTD) profiler. Although XCTD profilers can be used while the ship is sailing, temperature and depth profiles can be obtained for one location with each deployment. Since the depth data measured by an XCTD profiler is the result of a calculation involving the time and speed of falling, it is not a very accurate measurement technique. Furthermore, the XCTD probes must be abandoned in the sea after the experiment is completed. This situation not only causes waste, but it is also not conducive to the protection of the natural environment $[14,15]$. Moreover, the comparison test done by Flierl et al. in 2010 also confirmed that expendable bathythermograph (XBT) produces large systematic errors and insufficient data precision [16]. In 2004, Liu et al. used the moving vessel profiler (MVP) to measure temperature, salinity, and depth along sections at the mouth of the Zhujiang River and off the eastern Vietnamese coast. Since the MVP has only one temperature and depth sensor, the spatial resolution of the acquired temperature-depth profile is not high. The MVP system also has the disadvantages of being highly complex, takes up a large volume of space, and involves high maintenance costs [17]. The first operational use of the underway conductivity-temperature-depth (UCTD) profiler occurred during a cruise in 2004, the purpose of which was to examine the effect of internal waves and spice on long-range acoustic propagation northeast of Hawaii. However, UCTD profiles have a low spatial resolution, and data cannot be read in real time [18].
In summary, the temperature and depth sensors made from thermistors and piezoelectric elements, respectively, have the disadvantages of low efficiency when applied to oceanographic measurements [19], and only marine dynamic environmental parameters of a low temporal and spatial resolution can be obtained. These parameters are far from enough for the study of mesoscale vortices, fronts, and internal waves in the ocean $[20,21]$.

In order to solve the problem of low efficiency and low spatial resolution, sensor arrays based on FBGs for obtaining seawater temperature and depth profiles were proposed in [22-24]. Researchers have solved the compromise that typically arises between high sensitivity and fast response times of FBG temperature sensors through a special encapsulation process [25], and have remedied the problem of temperature cross-sensitivity of FBG pressure sensors by using temperature-compensated algorithms and the metallized diaphragm encapsulation process [26]. The sensor array is capable of obtaining a vertical profile of high spatial resolution of temperatures and depths from a few hundred meters below sea level to the sea surface, and is capable of real-time and continuous monitoring. The horizontal resolution is improved from 15 nautical miles for previous station observations and $2 \mathrm{~km}$ for MVP arrays to about $2 \mathrm{~m}$, and the observation ability is improved substantially.

\section{Sensor}

\subsection{Encapsulation technology}

As is the case for FBG sensor encapsulation technology, it is necessary to encapsulate effectively to improve the sensitivity of sensors, reduce their response time, and solve the problem of cross-sensitivity of temperature and pressure to ensure an accurate, timely, and effective water temperature-depth profile data acquisition instrument. 


\subsubsection{Encapsulation of temperature sensor and temperature compensation sensor}

In this study, the special encapsulation process we adopted not only effectively prevents FBGs chirping, but also eliminate the influence of pressure. The chirp of FBGs is the change in the period of the FBG structure along the length of the grating. FBGs were coated with a layer of silica gel, and we encapsulated each temperature sensor in a metal tube. The FBG and metal tube were fixed by a special glue named EPO-TEK $353 \mathrm{ND}$, which was a heat-curing epoxy resin for high-temperature conditions. We first placed the EPO-TEK 353ND in a vacuum pump to remove internal bubbles. Then, it was drawn into the metal tube by negative pressure pumping. Each end of the tube was covered by silicone rubber to protect the FBGs from getting wet. The reason for these set-ups is to ensure as much as possible that the FBG is only sensing external temperatures, with no effect from external stress, hence avoiding the chirping and influence of pressure. Figure 1(a) shows the encapsulation sketch of the temperature sensor.

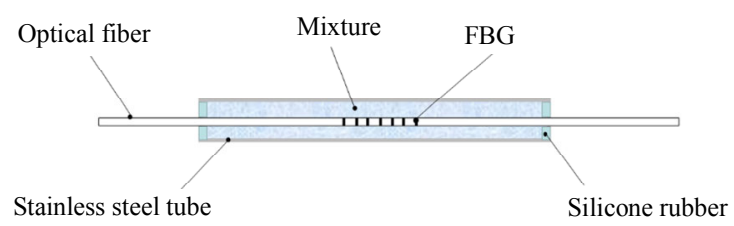

(a)

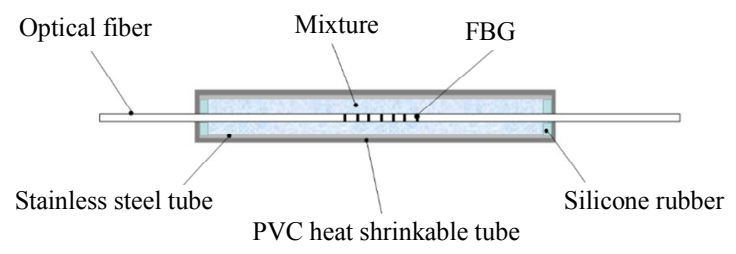

(b)

Fig. 1 Sketch of (a) the temperature sensor encapsulation and (b) the temperature compensation sensor encapsulation.

In order to reduce the response time of the temperature-compensated sensor, we covered an ordinary temperature sensor with PVC (polyvinyl chloride) thermoplastic tubing as a temperature compensation sensor, as shown in Fig. 1(b). We assembled the PVC thermoplastic tubes so as to extend the response time of the temperature compensation sensor in order to make the temperature compensation sensors and pressure sensors response at approximately the same time, which in this case is 0.2 seconds, and is considered acceptable.

\subsubsection{Encapsulation of pressure sensor}

We used a laser to weld the metallized fibers to the pressure diaphragm and prestress the fiber to improve the sensitivity of the sensor. The metal plating on both ends of the FBGs is an alloy of nickel and gold. Before welding the ends of the FBGs to the pressure diaphragm, we applied pre-stress on the FBGs to stretch them, resulting in higher sensitivity than that without pre-stress. Figure 2 shows the encapsulation sketch of the pressure sensor.

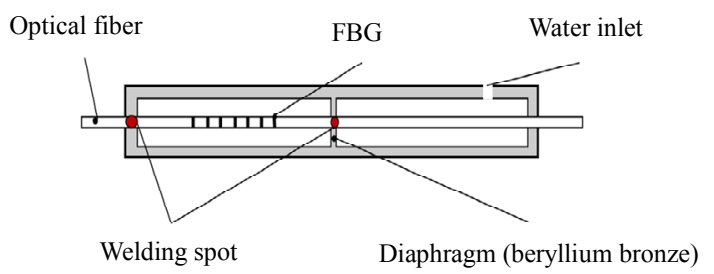

Fig. 2 Sketch of the pressure sensor encapsulation.

\subsection{FBG temperature sensors' working principle and sensitivity}

The FBG sensor is based on the photosensitivity principle of optical fibers. A photosensitive fiber grating is a fiber whose core refractive index is periodically modulated in the axial direction. This is a one-dimensional grating with two main parameters, the refractive index increment $\Delta n$ and the periodicity of the grating $\Lambda$. When the period is equal to half the wavelength of the incident light, the grating couples the incident fundamental mode and the reflected fundamental mode, presenting a wavelength-selective reflection function. The wavelength of the reflected light, referred to as the Bragg wavelength, is given by the Bragg equation as follows:

$$
\lambda_{B}=2 n_{\mathrm{eff}} \Lambda
$$


where $\lambda_{B}$ is the wavelength of the reflected light, $n_{\text {eff }}$ is the effective refractive index of the fiber core, and $\Lambda$ is the period of the grating. Researchers have attached FBGs to materials with large thermal expansion coefficients for packaging to improve the sensitivity of FBG. The equation for sensitivity is expressed as follows [27]:

$$
K_{T}=\lambda_{B}\left[(\alpha+\xi)+\left(1-P_{\varepsilon}\right)\left(\alpha_{s}-\alpha\right)\right]
$$

where $K_{T}$ is the temperature sensitivity, $\alpha$ is the thermal expansion coefficient of the FBG, $\xi$ is the thermo-optic coefficient, $P_{\varepsilon}$ is the elastic-optic constant, and $\alpha_{s}$ is thermal expansion coefficient of substrate material $K_{T}$ (see Table 1). FGB.

Table 1 Parameters for the temperature sensitivity (2) for the

\begin{tabular}{cc}
\hline Parameter & Value \\
\hline$\lambda_{B}(\mathrm{~nm})$ & 1529.81 \\
$\alpha\left({ }^{\circ} \mathrm{C}\right)$ & $0.55 \times 10^{-6}$ \\
$P_{\varepsilon}$ & 0.22 \\
$\alpha_{s}\left(/{ }^{\circ} \mathrm{C}\right)$ & $13.7 \times 10^{-6}$ \\
$\xi\left(/{ }^{\circ} \mathrm{C}\right)$ & $6.67 \times 10^{-6}$ \\
$K_{T}\left(\mathrm{pm} /{ }^{\circ} \mathrm{C}\right)$ & 26.74 \\
\hline
\end{tabular}

\subsection{Working principle and sensitivity of the FBG pressure sensors}

The structure of the pressure sensor used in this paper is shown in Fig. 2. When the elastic diaphragm is subjected to external pressure, longitudinal displacement of the center of the diaphragm will occur. We fixed the metallized fiber in the center of the diaphragm by soldering, so that the deflection of the diaphragm can be directly transmitted to the fiber grating. In this way, the measurement of the external pressure is converted into a measurement of the central wavelength of the fiber grating $(B, 1)$. Through a derivation based on [28], the relationship between the amount of wavelength change $\left(\Delta \lambda_{B}\right)$ and the external pressure $(q)$ can be given as

$$
\Delta \lambda_{B}=\left(1-P_{\varepsilon}\right) \lambda_{B} \frac{\pi R^{2} / 4}{4 \pi L E_{1} h^{3} / 3 R^{2}\left(1-\mu_{1}^{2}\right)+E_{2} s} q
$$

where $P_{\varepsilon}$ is the elastic-optic constant, $R$ is the radius of the diaphragm, $h$ is the thickness of the diaphragm, $L$ is the effective length of FBG, $E_{1}$ is the elastic modulus of the diaphragm material, $\mu_{1}$ is Poisson's ratio of the diaphragm material, $E_{2}$ is the elastic modulus of the fiber, and $S$ is the cross-sectional area of the fiber before loading (see Table 2).

Table 2 Parameters describing the various parameters of the sensor as employed in (3) for the relationship between the wavelength change and external pressure.

\begin{tabular}{cc}
\hline Parameter & Value \\
\hline$P_{\varepsilon}$ & 0.22 \\
$\lambda_{B}(\mathrm{~nm})$ & 1550 \\
$R(\mathrm{~mm})$ & 6 \\
$h(\mathrm{~mm})$ & 6.5 \\
$L(\mathrm{~mm})$ & 10 \\
$E_{1}(\mathrm{GPa})$ & 55 \\
$\mu_{1}$ & 0.42 \\
$E_{2}(\mathrm{GPa})$ & 25 \\
$\mathrm{~S}\left(\mu \mathrm{m}^{2}\right)$ & 5.024 \\
$\frac{\Delta \lambda_{B}}{q}(\mathrm{pm} / \mathrm{MPa})$ & 1601.845 \\
\hline
\end{tabular}

\subsection{Problem of temperature cross-sensitivity}

The FBG pressure sensors for measuring ocean depth use the FBG temperature sensors for their temperature compensation. Although FBG pressure sensors and their corresponding temperature compensation sensors are both sensitive to temperature, the inconsistent response time as described above can cause deviations in the depth data as the sensor array reaches the cold-water mass boundary. FBGs of ordinary FBG temperature sensors that are wrapped in a metal tube and a layer of glue (see above) can be regarded as being double tube structures, whose response times are quite different from the response times of the FBG pressure sensors, which are wrapped in a metal tube and a layer of air. The corresponding theoretical calculation to determine the time required for the heat conduction is given as follows [29]:

$$
\begin{aligned}
& \frac{T_{f}-T_{2}}{T_{f}-T_{1}}=\exp \left[-\frac{\Gamma(2 d+2 a+r)}{\rho c_{p}(d+2 a+r) d} t\right] \\
& t=-\frac{\rho c_{p}(d+2 a+r) d \ln \left(\frac{T_{f}-T_{2}}{T_{f}-T_{1}}\right)}{\Gamma(2 d+2 a+r)}
\end{aligned}
$$


where $T_{f}$ is the temperature of the environment, $T_{2}$ is the metal tube axial temperature, when $t$ is the response time of the senor and is set to zero, $T_{2}$ is equal to $T_{1}, \Gamma$ is the heat transfer coefficient of the metal surface, $d$ is the thickness of the wall, $a$ is the spacing between the grating and the tube wall, $r$ is the diameter of the fiber, and $\rho$ and $c_{p}$ are the density and specific heat capacity, respectively, of the metal casing materials.

Table 3 Parameters used to determine the response time between the temperature and pressure FBG sensors (5).

\begin{tabular}{ccc}
\hline Parameter & $\begin{array}{c}\text { FBG pressure } \\
\text { sensor }\end{array}$ & FBG temperature sensor \\
\hline$T_{1}\left({ }^{\circ} \mathrm{C}\right)$ & 0 & 0 \\
$T_{f}\left({ }^{\circ} \mathrm{C}\right)$ & 43 & 43 \\
$T_{2}\left({ }^{\circ} \mathrm{C}\right)$ & 29.5 & 29.5 \\
$d(\mathrm{~mm})$ & 5 & 0.275 \\
$\rho\left(\mathrm{kg} \cdot \mathrm{m}^{-3}\right)$ & $9.8 \times 10^{3}$ & $7.75 \times 10^{3}$ \\
$c_{p}\left(\mathrm{~J} \cdot \mathrm{kg}^{-1} \cdot \mathrm{K}^{-1}\right)$ & 990 & 286 \\
$a(\mathrm{~m})$ & $5 \times 10^{-3}$ & $6 \times 10^{-5}$ \\
$r(\mathrm{~mm})$ & 0.125 & 0.125 \\
$\Gamma\left(\mathrm{W} \cdot \mathrm{m}^{-1} \cdot \mathrm{K}^{-1}\right)$ & $1.5 \times 10^{4}$ & $1.5 \times 10^{4}$ \\
$t(\mathrm{~s})$ & 3.61 & 0.047 \\
\hline
\end{tabular}

Considering the results of FBG pressure and temperature sensors' response time in Table 3, the metal outer tube of the FBG temperaturecompensation sensor is filled with a thermoplastic polymer material with a length of $10 \mathrm{~mm}$ and a thickness of $1.25 \mathrm{~mm}$. The test results show that the response time of the temperature compensation sensor is $3.41 \mathrm{~s}$, which is consistent with the temperature response time of the FBG pressure sensor. The response time comparison chart is presented in Fig. 3.

Since the distance between the FBG pressure and temperature compensation sensors on the sensing array is about $10 \mathrm{~cm}$, and the temperature change of the seawater is essentially constant at the centimeter scale, the difference due to the sensor's position is negligible. When the pressure sensor makes contacts with the cold-water mass boundary during the seaborne tests in Yellow Sea China, the influence of the inconsistent response of the FBG pressure sensor and the temperature compensation sensor has been substantially eliminated.

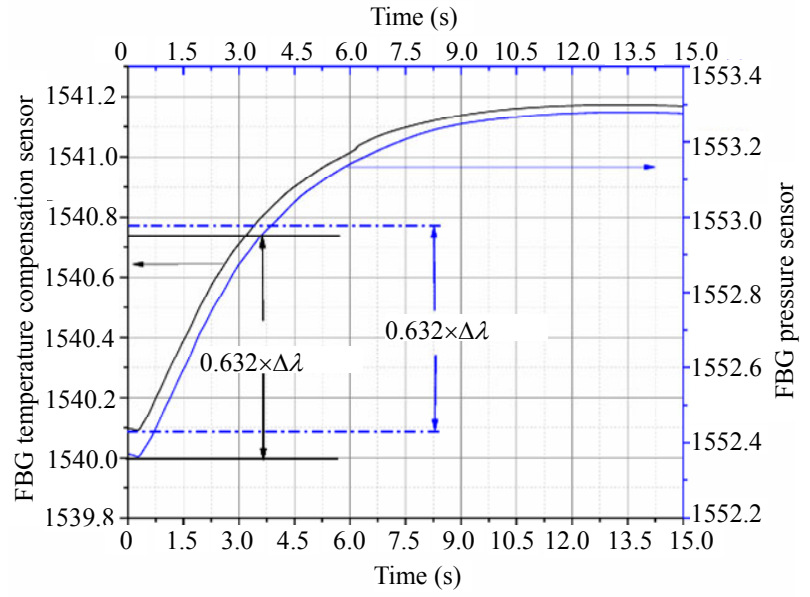

Fig. 3 FBG pressure and temperature compensation sensors' response time comparison diagram.

\subsection{Calibration methodology}

Prior to deploying the sensors, a calibration test was conducted to ensure that the sensitivity of the sensors met the necessary demands for their applications at sea. The sensors were calibrated in an electro-thermostatic water cabinet as shown in Fig. 4 at a constant temperature. The FBG pressure sensor, FBG temperature compensation sensor, and Sea-Bird Electronics 56 series' temperature sensors (SBE56) were placed together in the pressure tank for the pressure calibration experiment (see Fig.4).

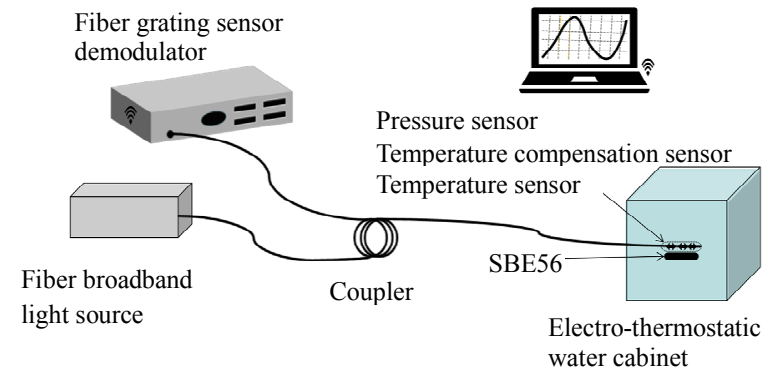

(a)

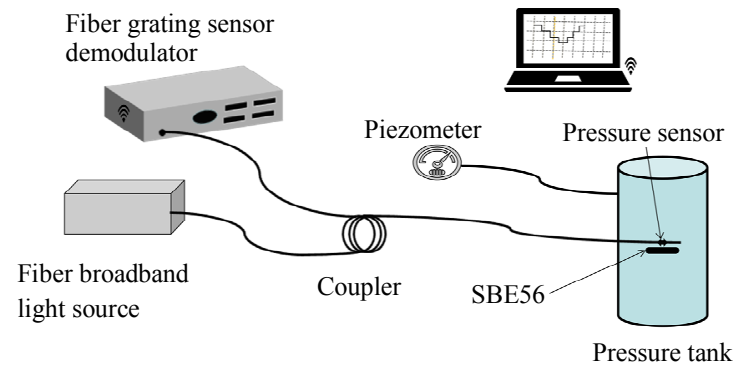

(b)

Fig. 4 Experimental setup for calibrating the (a) temperature and (b) pressure sensors. 
Under constant pressure conditions, a temperature change experiment on the FBG pressure sensor was carried out. In order to ensure the accuracy of the data, we averaged the value of the FBG pressure sensor for 2 minutes and did the same for the standard temperature sensors (SBE56) at the corresponding time. In this way, a linear function of the temperature response of the pressure sensor may be obtained, where the slope represents the temperature compensation factor of the pressure sensor, as outlined in Table 4 and Fig. 5. From Fig. 5, we can conclude that the sensitivity of the pressure sensor to temperature is $29.87 \mathrm{pm} /{ }^{\circ} \mathrm{C}$.

Table 4 FBG pressure sensor temperature calibration data.

\begin{tabular}{cc}
\hline Temperature $\left({ }^{\circ} \mathrm{C}\right)$ & Wavelength $(\mathrm{nm})$ \\
\hline 1.99459 & 1552.30222 \\
4.98527 & 1552.38985 \\
9.97524 & 1552.53583 \\
14.96481 & 1552.68260 \\
19.95645 & 1552.82989 \\
24.94638 & 1552.97997 \\
29.93898 & 1553.13342 \\
34.93251 & 1553.28850 \\
\hline
\end{tabular}

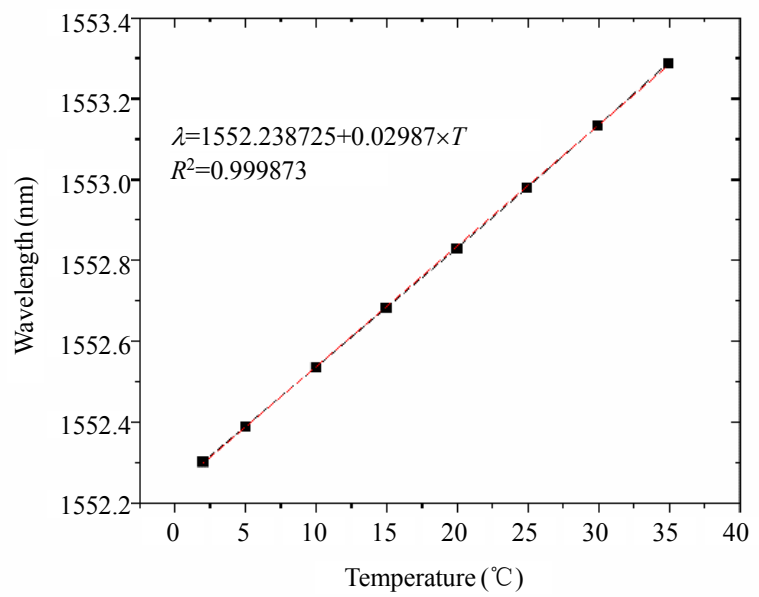

Fig. 5 Temperature calibration results for the FBG pressure sensor.

The FBG pressure sensor was then placed in a pressure tank for the pressure calibration, and the temperature in the pressure tank was measured in real time using the SBE56 sensors. Considering the temperature value measured by the SBE56 sensor, the temperature value corresponding to the FBG pressure sensor was then determined. The wavelength value measured by the FBG pressure sensor minus the wavelength change caused by the temperature change is taken as the final pressure value. The equation for the pressure and the central wavelength of the FBG pressure sensor is then determined by fitting a linear relationship by the least squares to the data (see Table 5 and Fig. 6). From Fig. 6, we can conclude that the sensitivity of the FBG pressure sensor reaches $1611 \mathrm{pm} / \mathrm{MPa}$, and the linear correlation coefficient reached 0.999852 .

Table 5 FBG pressure sensor pressure calibration data.

\begin{tabular}{cc}
\hline Pressure $(\mathrm{kP})$ & Wavelength $(\mathrm{nm})$ \\
\hline 1000 & 1553.87446 \\
800 & 1553.541562 \\
600 & 1553.214429 \\
400 & 1552.891765 \\
200 & 1552.574756 \\
0 & 1552.263834 \\
\hline
\end{tabular}

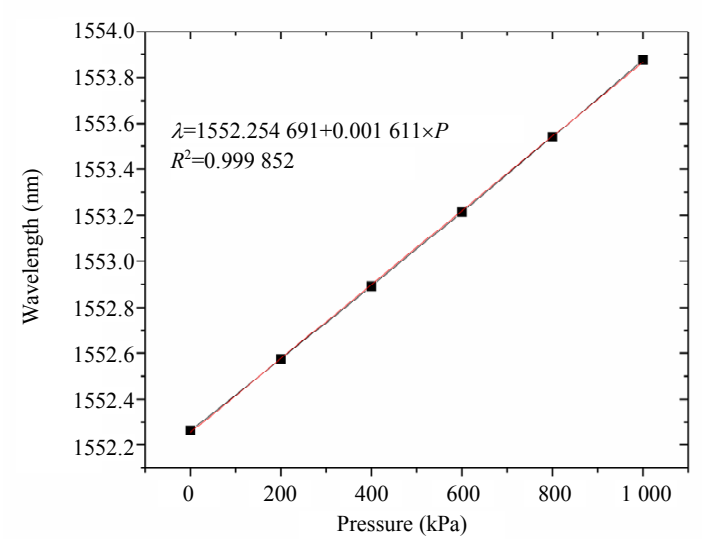

Fig. 6 Linear calibration curve of the calibration data for the pressure sensor.

\section{Seaborne tests in the Yellow Sea of China}

The special hydrological characteristics of the Yellow Sea area are more conducive to the advantages of the FBG sensing array. The cold-water mass is a typical feature of the Yellow Sea. The temperature and salinity of the seawater change very sharply in the horizontal direction of the cold-water mass. The advantage of the FBG sensing array is that the horizontal resolution of the temperature observation is high, which is more conducive to determining and detailing the location of the cold-water front.

In terms of economic significance, the Yellow Sea area is an important sea area for aquaculture. 
The economic benefits of aquaculture are closely related to the hydrological characteristics. Changes in the front of the cold-water mass would have a significant impact on aquaculture, so it is of great economic importance to pay close attention to the hydrological characteristics of the seawater surrounding the cold-water front.

\subsection{System structure of seaborne tests}

The towed ocean temperature-depth profile continuous measurement system consists of two parts: the temperature-depth sensor array, which includes the temperature sensors, pressure sensors, and a wire rope, and the interrogation system, which includes a laser source, detector, light switch, and control circuit. A single string of the sensor chain is made up of 10 temperature sensors, one pressure sensor, and one temperature compensated sensor which eliminates the effects of temperature on the pressure sensor. The spacing between the FBG temperature sensors is about $5 \mathrm{~m}$, while the spacing between the FBG pressure and temperature compensation sensors is about $10 \mathrm{~cm}$. The three sensor chains and one wire rope are assembled together. The electrical sensors were tied to the FBG sensor array entering the seawater for measurement, as shown in Fig. 7, with Fig. 8 showing photos of the FBG sensor array while the ship was sailing, along with a schematic diagram of the sensor chain.

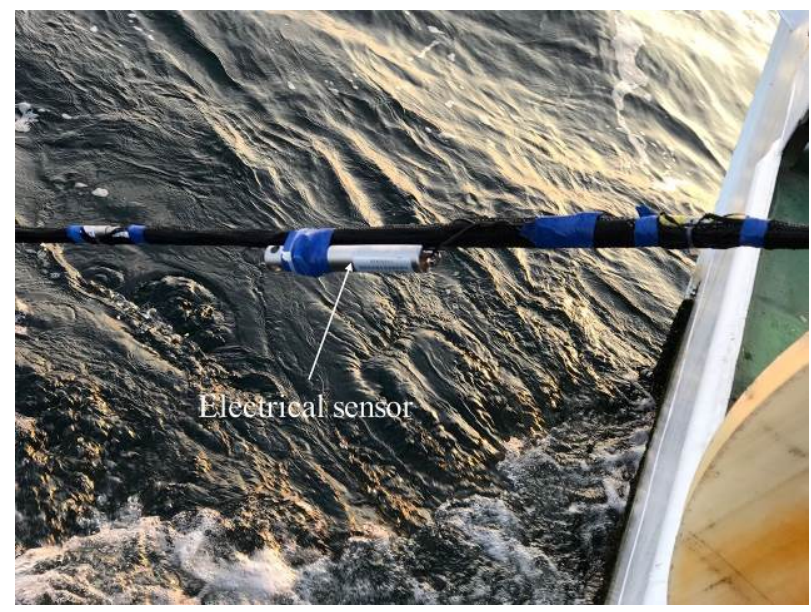

Fig. 7 Sensors entering the seawater.

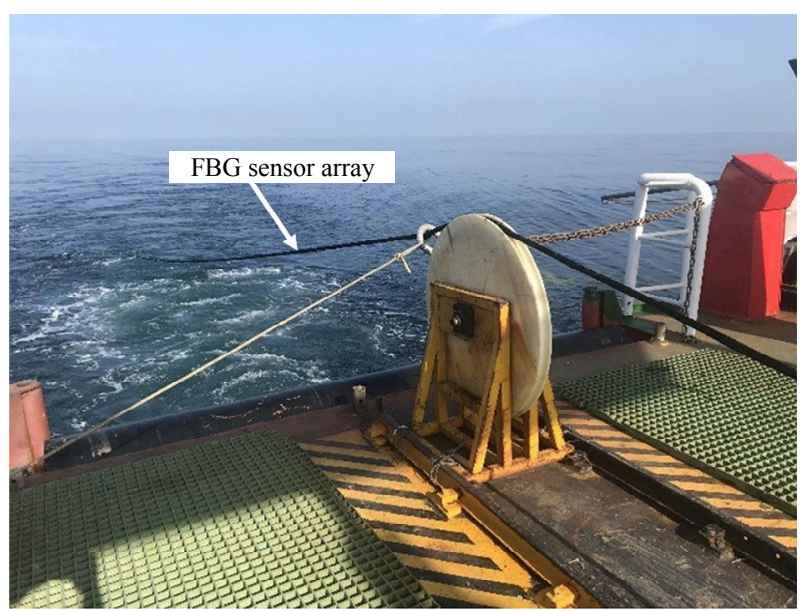

(a)

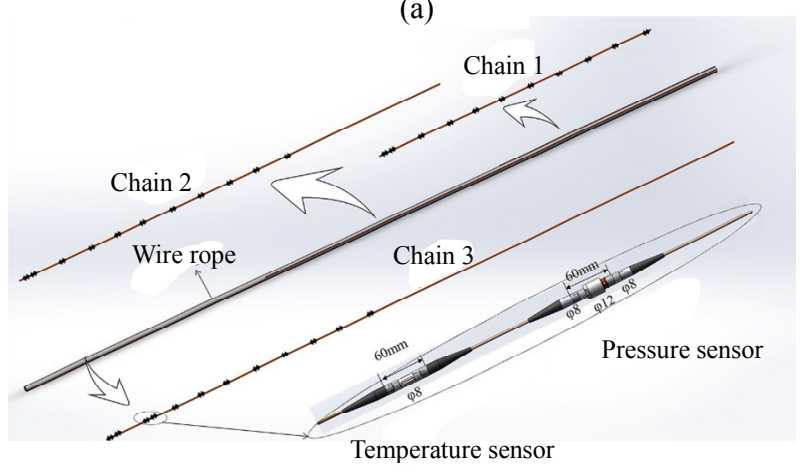

(b)

Fig. 8 Sensor array physical picture (a) and diagram (b).

\subsection{Experimental data and analysis}

The data measured by the optical fiber grating temperature sensors were consistent with the SBE56 data (see Fig. 9). A portion of the FBG sensor and SBE56 datasets is discussed here for the sake of comparison. FBG sensors numbered 4-583 (a

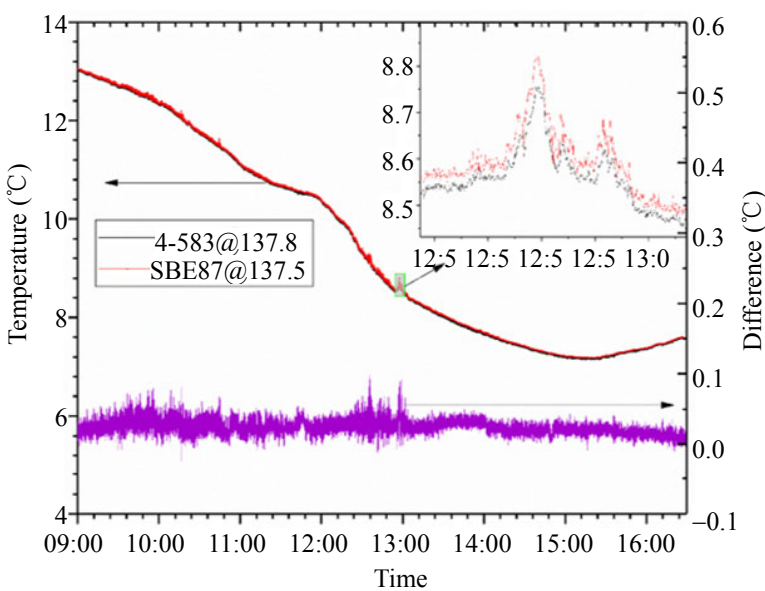

Fig. 9 Data comparison between the FBG temperature sensor numbered 4-583 and the Sea-Bird Electronics 56 series' temperature sensors temperature sensor numbered 87 . 
unique code allocated to the sensors on their production) were fixed on the sensor chain $30 \mathrm{~cm}$ away from SBE56, which has a designation number of 87. Theoretically, the 4-583 sensors would show slightly lower temperatures due to their slightly deeper position in the water.

The sensor chain contacted the seabed during the towing process, as evident from the GPS's onboard data and the fiber sensor data, with the seabed topography obtained by single-beam echo sounding. The goal is to further illustrate the reliability of the data collected by the FBG sensing array by comparing the data collected with electrical sensors. We obtained depth data that are very consistent with the Alec ATD-HG electrical pressure sensor and TD. The depth data measured by the sensors are shown in Fig. 10.

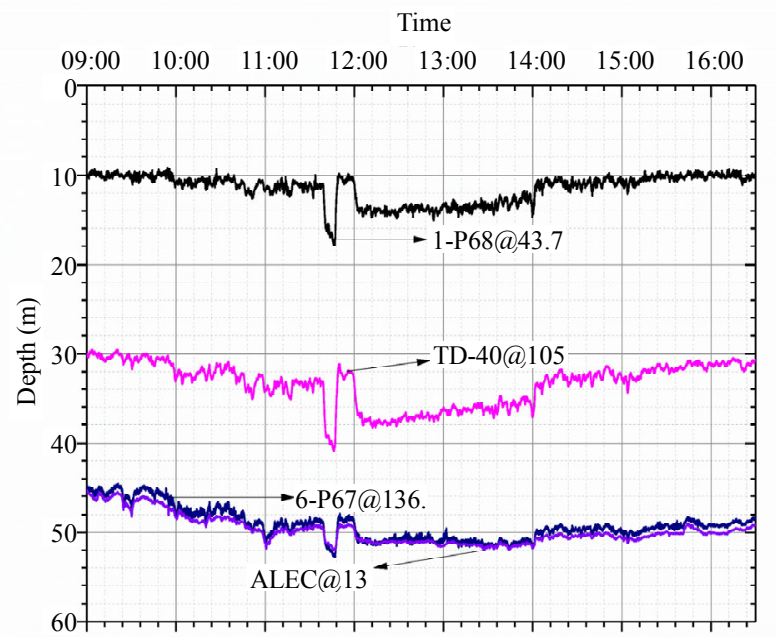

Fig. 10 Data summary of the FBG depth sensor and the electrical depth sensor.

The temperature data were used to plot a temperature and depth profile of the North Yellow Sea accordingly. In Fig. 11, the $x$-axis represents latitude, the $y$-axis represents depth, with the colors representing temperature.

The sampling frequency of the all-fiber seawater temperature and depth profile measurement system is $1 \mathrm{~Hz}$, the accuracy of the FBG sensors reaches $0.01{ }^{\circ} \mathrm{C}$., and the accuracy of the FBG depth sensors reaches $0.1 \%$ of the full scale. The amount of data collected was so large and accurate that the cold-water mass boundary was clearly evident. We found that the lowest temperature of the cold-water mass in mid-October was $7.15{ }^{\circ} \mathrm{C}$, and that the transition zone between the cold-water mass and the surrounding water was fairly narrow. This is seen by how the bottom cold water sees a transition between $38.14{ }^{\circ} \mathrm{N}$ with a temperature of $11{ }^{\circ} \mathrm{C}$ to $7.2^{\circ} \mathrm{C}$ at $38.24^{\circ} \mathrm{N}$, a distance of only $10 \mathrm{~km}$, leading to a temperature gradient reaching up to $1.2^{\circ} \mathrm{C} / \mathrm{m}$.

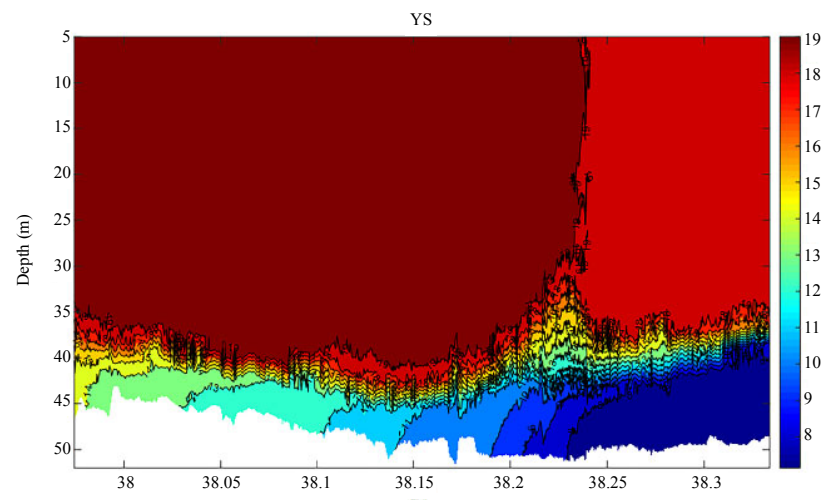

Fig. 11 Temperature-depth profile of the North Yellow Sea.

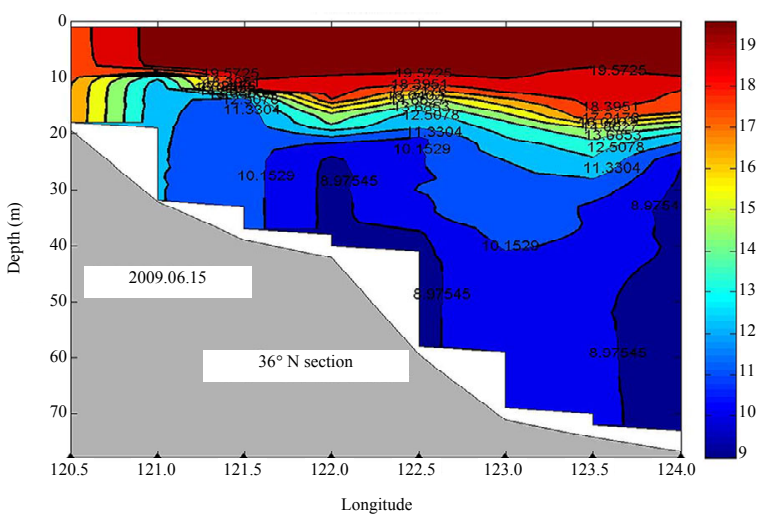

(a)

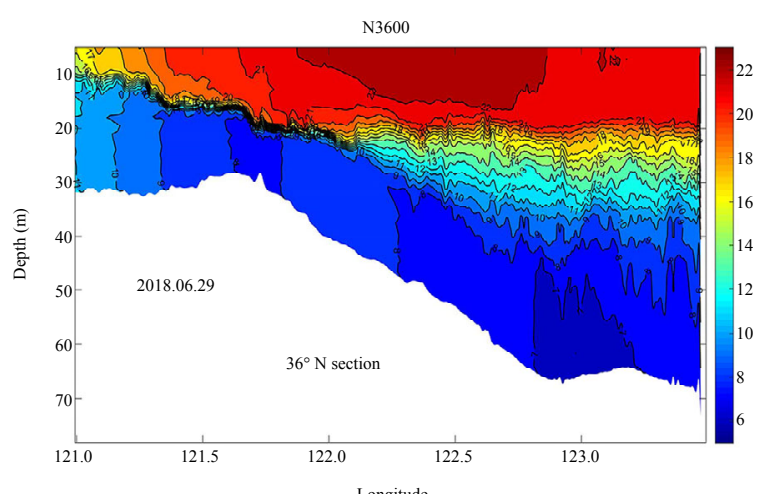

(b)

Fig. 12 Comparison of FBG sensor array and autonomous underwater vehicle (AUV) test data: (a) measured by autonomous underwater vehicle (AUV) and (b) measured by FBG sensor array. 
In the observation of cold-water masses, compared to measuring by AUV, the front of the cold-water mass observed by the FBG sensor array is more obvious, as shown in Fig. 12. The horizontal resolution is changed from 55 kilometers of AUV to 2 meters of FBG sensing array. The success of our seaborne tests suggests that the fiber optical grating temperature-depth sensing system has notable potential applications.

\section{Conclusions}

Since the observation stations using electrical sensors such as AUV are sparse, the observation results are affected by the employed interpolation method. Our tests in the Yellow Sea produce very accurate and valuable data which clearly delineate the current border of the Yellow Sea cold water mass. Previously, due to the sparse locations of the fixed-point CTD observation stations, accurate thermocline position data could not be obtained. It had therefore been assumed that the temperature in this sea area changed slowly before. However, according to the temperature depth profile data measured by the FBG sensing array, the specific position and temperature transition data of the thermocline can be clearly plotted. We found that the previous assumptions were inaccurate. The temperature does not change evenly and slowly, but after a certain position, the change is very fast. In addition to the accuracy of the FBG sensor array, the high spatial resolution of its seawater temperature-depth measurements represents an important contribution to oceanographic studies.

In the future, researchers plan to improve the system by including encapsulation and demodulation to further enhance the sensor performance.

\section{Acknowledgment}

We thank for the financial support of the National Natural Science Foundation of China (Grant No. 41276094), the Strategic Priority
Research Program (Grant No. XDA110-40201), and the senior User Project of RV KEXUE (Grant No. KEXUE201XGXX).

Open Access This article is distributed under the terms of the Creative Commons Attribution 4.0 International License (http://creativecommons.org/licenses/by/4.0/), which permits unrestricted use, distribution, and reproduction in any medium, provided you give appropriate credit to the original author(s) and the source, provide a link to the Creative Commons license, and indicate if changes were made.

\section{References}

[1] C. Campagna, A. L. Rivas, and M. R. Marin, "Temperature and depth profiles recorded during dives of elephant seals reflect distinct ocean environments," Journal of Marine Systems, 2000, 24(3): 299-312.

[2] R. W. Herschy, Hydrometry principles and practice. New York: John Wiley and Sons, 2000.

[3] J. R. Holton, "An introduction to dynamic meteorology," American Journal of Physics, 1973, 41(5): 752-754.

[4] A. Badan-Dangon, C. E. Dorman, M. A. Merrifield, and Clinton D. Winant, "The lower atmosphere over the Gulf of California," Journal of Geophysical Research Oceans, 1991, 96(C9): 16877-16896.

[5] G. Cervone, "Combined remote-sensing, model, and in situ measurements of sea surface temperature as an aid to recreational navigation: crossing the Gulf Stream," International Journal for Remote Sensing, 2013, 34(2): 434-450.

[6] D. G. Myers and P. T. Hick, "An application of satellite-derived sea surface temperature data to the Australian fishing industry in near real-time," International Journal of Remote Sensing, 1990, 11(11): 2103-2112.

[7] Z. J. Zhang, Y. Cai, Fan W, J. Ruan, and G. Z. Chai, "Study on robustness of underwater acoustic temperature field measurement method," Journal of Zhejiang University of Technology, 2012, 40(2): 172-177.

[8] F. H. Mei and W. Hou, "Application of non-acoustic submarine detection technology in aviation antisubmarine of trailing detection," Electronics Optics \& Control, 2017, 27(7): 62-65.

[9] R. Pollard, "Frontal surveys with a towed profiling conductivity/temperature/depth measurement package (Sea Soar)," Nature, 1986, 323(6087): 433-435.

[10] C. Sheppard, "Large temperature plunges recorded by data loggers at different depths on an Indian 
Ocean atoll: comparison with satellite data and relevance to coral refuges," Coral Reefs, 2009, 28(2): 399-403.

[11] D. Dinesh, L. Gabriel, T. Daniel, N. Thomas, L. Elfed, and D. Gerard, "Underwater depth and temperature sensing based on fiber optic technology for marine and fresh water applications," Sensors, 2017, 17(6): 1228.

[12] M. Tsuchiya, L. D. Talley, and M. S. McCartney, "Water-mass distributions in the Western South Atlantic; A section from South Georgia Island (54S) northward across the equator," Journal of Marine Research, 1994, 52(1): 55-81.

[13] S. Bhansali, L. C. Langebrake, and S. Bhat, "MEMS based conductivity-temperature-depth sensor for harsh oceanic environment," OCEANS Proc. of IEEE, 2006, 2: 1785-1789.

[14] C. Albérola, C. Millot, U. Send, C. Mertens, and J. L. Fuda, "Comparison of XCTD/CTD data," Deep Sea Research Part I Oceanographic Research Papers, 1996, 43(6): 859-876.

[15] B. M. Sloyan, L. D. Talley, T. K. Chereskin, R. Fine, and J. Holte, "Antarctic intermediate water and subantarctic mode water formation in the Southeast Pacific: the role of turbulent mixing," Journal of Physical Oceanography, 2008, 40(7): 1558-1574.

[16] G. R. Flierl and A. R. Robinson, "XBT Measurements of Thermal Gradients in the MODE Eddy," Journal of Physical Oceanography, 2010, 7(7): 300-301.

[17] C. J. Liu, H. B. Mao, R. Y. Chen, and D. X. Wang, "An analysis on moving vessel profiler observation in Northern South China sea in September 2004," Journal of Tropical Oceanography, 2005, 24(5): 77-82.

[18] D. L. Rudnick and J. Klinke, "The underway conductivity temperature depth instrument," Journal of Atmospheric \& Oceanic Technology, 2007, 24(11): 1910-1923.

[19] S. Hisamune, K. Amagai, N. Kimura, and K. Kishida,
"A study of factors relating to work accidents among seamen," Industrial Health, 2006, 44(1): 144-149.

[20] D. B. Chelton and S. P. Xie, "Coupled ocean-atmosphere interaction at oceanic mesoscales," Oceanography, 2010, 23(4): 52-69.

[21] K. V. S. R. Prasad, "Space borne SAR observations of oceanic internal waves in North Bay of Bengal," Natural Hazards, 2011, 57(3): 657-667.

[22] J. X. Song, Q. Jiang, Y. Y. Huang, Y. B. Li, Y. X. Jia, $\mathrm{X}$. W. Rong, et al., "Research on pressure tactile sensing technology based on fiber Bragg grating array," Photonic Sensors, 2015, 5(3): 1-10.

[23] C. R. Dennison, D. A. Singlehurst, and P. M. Wild, "A distributed pressure measurement system comprising multiplexed in-fibre Bragg gratings within a flexible superstructure," Journal of Lightwave Technology, 2012, 30(1): 123-129.

[24] J. W. Arkwright, I. D. Underhill, S. A. Maunder, A. Jafari, and N. Cartwright, "Fiber optic pressure sensing arrays for monitoring horizontal and vertical pressures generated by traveling water waves," IEEE Sensors Journal, 2014, 14(8): 2739-2742.

[25] D. P. Zhang, J. Wang, Y. J. Wang, and X. Dai, “A fast response temperature sensor based on fiber Bragg grating," Measurement Science \& Technology, 2014, 25(7): 75-105.

[26] M. J. Guo, D. S. Jiang, and H. C. Yuan, "Low temperature properties of fiber Bragg grating temperature sensors with two package methods," Optics \& Precision Engineering, 2007, 15(3): 326-330.

[27] Z. Bo, G. S. Yan, and Y J. Deng, "Cross-sensitivity of fiber grating sensor measurement," Journal of Applied Optics, 2007, 28(5): 5-9.

[28] Z. C. Le, "Design of strain diaphragm using in the microbend fiber-optic pressure sensor," Optics \& Precision Engineering, 1994, 2895: 28-95.

[29] Y. Q. Liu, Z. Y. Guo, Y. Zhang, K. S. Chiang, and X. Y. Dong, "Simultaneous pressure and temperature measurement with polymer-coated fiber Bragg grating," Electronics Letters, 2000, 36(6): 564-566. 